\title{
A cien dias del primero de mayo
}

A principios de este mes, alcaldes y legisladores, electos el 16 de marzo y posesionados el $1^{\circ}$ de mayo del año en curso, culminaron sus primeros cien días de labores. Ahora, si bien es cierto que poco más de tres meses de gestión es un lapso de tiempo muy corto para dar un veredicto definitivo con respecto al desempeño de los nuevos funcionarios - en especial si se toma en cuenta la envergadura de los problemas que estos, en sus respectivas esferas, han debido enfrentar-, una evaluación de este primer período de labores, tanto en el Organo Legislativo como en las administraciones municipales, resulta, además de útil, conveniente. En primer lugar, porque una evaluación de los primeros cien días en la administración edilicia y en el quehacer legislativo puede establecer qué tan acertados fueron los pronósticos y qué tan realistas fueron las expectativas que se generaron en tomo a los resultados electorales. En segundo lugar, porque el escándalo del fraude en el sistema financiero, dadas su dimensión y consecuencias, ha acaparado la opinión pública y las preocupaciones de los analistas, lo cual ha permitido que la culminación de este primer periodo postelectoral pase, prácticamente, desapercibido y que los análisis que generalmente aparecen en el campo de debate hayan brillado por su ausencia.

\section{Las administraciones edilicias}

Uno de los más duros golpes asestados a ARENA en las pasadas elecciones fue la pérdida de la alcaldía de San Salvador y, junto con ella, la de varias de las alcaldías más importantes del país. Al conocer los resultados electorales, el FMLN se dio a la tarea de proclamarse vencedor y autodenominarse "primera fuerza política del país"; los simpa- tizantes de izquierda pusieron toda su fe en la nueva racha de gobernantes con la que contarian las alcaldías e, incluso, no faltaron ex areneros desilusionados que, sin más remedio, decidieron otorgar a Héctor Silva y a sus nuevos homólogos el beneficio de la duda en materia de administración edilicia.

En definitiva, los nuevos alcaldes tomaron posesión de sus cargos en un clima de confianza y optimismo. Muchos pensaron que al fin habían llegado a las alcaldías quienes acabarian con la corrupción, la burocracia, la negligencia y toda la serie de males que hasta el momento había caracterizado el quehacer edilicio. Los nuevos alcaldes, varios de ellos recién involucrados en la política o en el desempeño de cargos públicos, hicieron gala de las mejores intenciones y aseguraron estar dispuestos a introducir mejoras substanciales en el funcionamiento de sus respectivas administraciones. Sin embargo, y a pesar de los buenos augurios, el resultado de los primeros cien días de labores en las nuevas alcaldías no ha sido precisamente el esperado.

En lo que respecta a la alcaldía capitalina, habrá que mencionar algunas dificultades que Héctor Silva, nuevo alcalde de la comuna, ha encontrado a la hora de hacerle frente a la administración de San Salvador. La primera crítica contundente de parte de la opinión pública a la gestión de Silva se produjo cuando éste decidió aumentar considerablemente los salarios de sus colaboradores al tiempo que creaba nuevas plazas en la dirección del municipio. Los empleados de la alcaldía fueron, por supuesto, los primeros en protestar y exigían, con razón, el aumento salarial que, anteriormente, habían acordado con el ex alcalde Mario Valiente. Se desconoce en qué concluyeron tales peticiones. Lo cierto es que éste no sería más que el principio de una serie 
de problemas que el nuevo alcalde se vería obligado a enfrentar. Poco después se dieron los temidos despidos que Silva consideró necesarios y pronto la Gerente de Mercados renunció, aduciendo incapacidad para ejercer el cargo. A este tipo de asuntos administrativos se sumaban el desorden e irregularidades que en materia financiera había dejado Valiente en la alcaldía y que, de no solventarse, amenazaban con volverse crónicos y dificultar aún más el desempeño en la comuna.

Hasta aquí lo referente a la conducción administrativa de la alcaldía, pero los problemas de la ciudad urgían de prontas respuestas que, efectivamente, se diferenciaran de las propuestas del ex alcalde arenero. En cuanto al problema de la basura, Héctor Silva se ha visto en serias dificultades debido a sus intentos por cumplir con la promesa de llevar a cabo los proyectos apegándose siempre a la concertación. Los habitantes de Tonacatepeque, lugar idóneo para la creación del relleno sanitario, se opusieron rotundamente a que éste funcionara en su municpio y con ello pusieron al alcalde capitalino en serias dificultades a la hora de decidir qué hacer con los miles de toneladas de desechos sólidos que diariamente arroja San Salvador. Al terminar sus primeros cien días de gestión $y$, probablemente, con más dificultades de las que se imaginó cuando se lanzó a la candidatura, Silva logró encontrar otro sitio para ubicar el relleno, pero decidió reservarse el nombre, so pena de enfrentar, nuevamente, el problema de la falta de consenso.

Las demás demandas acuciantes de San Salvador se encuentran, a diferencia del problema de la basura, esperando aún una solución certera e inteligente. Las ventas callejeras y el reordenamiento vehicular se perfilan como los problemas más difíciles de resolver. Sin embargo - a pesar de que en declaraciones previas reconoció que la mayor parte de las promesas hechas durante la campaña electoral pueden seguir considerándose como tales-, Silva se dio por satisfecho a la hora de rendir el informe de este primer período y explico que sus otros proyectos se llevarán a cabo a mediano y largo plazo.

Por otra parte, lejos de ser Héctor Silva el único de los nuevos ediles que se ha visto en problemas a la hora de tomar las riendas de la alcaldía, dificultades de distinta índole han caracterizado el quehacer de la mayor parte de las comunas ahora ocupadas por los partidos de oposición. La alcaldía de Santa Ana se declaró en la quiebra, mientras que las de Mejicanos y San Marcos, entre otras, encontraron serios problemas en las arcas municipales, hereda- dos por las pasadas administraciones areneras. En Ilopango, además de los cuantiosos déficits presupuestarios, los empleados mantuvieron durante varios días un paro de labores exigiendo aumento salarial. En Guazapa se presento una crisis cuando empeź a correr el rumor de que el consejo pedía la destitución del alcalde, Antonio Corado. En fin, son varios los casos que servirian para ilustrar las complicaciones en las que se han visto envueltos los ediles recientemente posesionados.

$Y$ es que los alcaldes de oposición han tenido que enfrentarse con la realidad y darse cuenta de que una cosa es que exista un plan de gobiemo municipal muy bien intencionado y profesionalmente elaborado, y otra muy distinta que dicho plan sea factible y reciba fácilmente la aceptación de la ciudadanía. Primero, porque las propuestas que llevaron a los actuales ediles a ocupar esos cargos fueron elaboradas desde fuera, sin el conocimiento intemo del manejo de las alcaldías y de las ciudades; segundo, porque poner en marcha un proyecto implica sortear todo tipo de obstáculos que van desde los malos manejos de administraciones anteriores, hasta las mismas costumbres de los habitantes de cada ciudad que muchas veces dificultan la concreción de cambios significativos. Finalmente, porque llegar a un cargo público nuevo obliga a aclimatarse en él y adaptarse a los mecanismos internos que permiten su funcionamiento; pero si, además, se arriba a dichos cargos con deseos renovadores, es necesario tener en cuenta que aquéllos han sido administrados durante años por manos corruptas y burocratizadas que generaron dinámicas que, aunque perjudiciales, hoy resultan difíciles de trastocar.

Así pues, muchos de los nuevos funcionarios que llegaron a la alcaldía con deseos de transformarla y de mejorar notoriamente sus ciudades se han visto enfrascados en la resolución de problemas meramente administrativos; han tenido que dedicarse a poner en orden las finanzas, debido a los canales y mecanismos de corrupción que las administraciones municipales areneras dejaron establecidos en las alcaldías; se han visto en problemas a la hora de manejar el personal de las municipalidades; y han tenido que enfrentarse directamente con una población cuyas costumbres, individualismo, insolidaridad y necesidades básicas insatisfechas constituyen, en sí mismas, problemas por resolver.

Según información de uno de los rotativos matutinos más importantes del pais, el actual alcalde 
capitalino, Héctor Silva, obtendría poco más de 4 en la calificación por su desempeño hasta ahora. Pero, más allá de la información de la prensa, lo cierto es que los nuevos ediles no han podido poner en marcha sus propuestas y las ciudades no han experimentado cambios notorios.

Por supuesto, ex alcaldes y funcionarios de ARENA no han perdido oportunidad para hacer declaraciones contra los actuales ediles y, con el cinismo más descarado, aseguran que los nuevos alcaldes se han dedicado a "llorar" y a lamentarse por lo que sus predecesores hicieron y por eso "no han hecho nada" por resolver los problemas de las alcaldías. Ante tal actitud cabe decir que si bien es cierto que aún no se ven mejoras palpables en los distintos municipios, también lo es que eso se debe, en gran medida, al nefasto legado que dejaron los gobiemos municipales anteriores, cuyas características principales fueron las prácticas corruptas y la ineficiencia administrativa. Si quienes ocuparon ya los cargos edilicios estuvieran realmente interesados en mejorar sus ciudades, prestarían su apoyo y conocimiento a las nuevas administraciones en lugar de dedicarse a descalificar a la oposición mediante argumentos bajos que lo único que logran es poner de manifiesto que su interés no va encaminado hacia la resolución de los problemas de los municipios, sino hacia el desprestigio de sus rivales políticos, con el único fin de adueñarse nuevamente de un poder que no supieron usar a favor de las comunidades.

De estos primeros cien días pueden sacarse, entonces, varias conclusiones importantes: en primer lugar, que si bien es cierto que no hay que perder la dosis de optimismo y la confianza en que la situación puede mejorar, también es conveniente ser realistas y entender que las buenas intenciones no son suficientes para modificar prácticas, tradiciones y situaciones que, aunque indeseables y daninas, están arraigadas en los hábitos de la gente $y$, por consiguiente, son muy difíciles de cambiar. En segundo lugar y por esas mismas razones, es necesario entender que los cambios no pueden darse inmediatamente; suele ser muy fácil ofrecer grandes soluciones a los problemas, pero la puesta en práctica de las propuestas pertenece a un orden de cosas distinto cuya complejidad no puede soslayarse. En tercer lugar, hay que señalar que una buena administración edilicia no depende únicamente del alcalde y su equipo, ya que en ella interviene también la sociedad civil, a la cual le corresponde, más que permanecer impasible frente a los múltiples y serios problemas que enfrentan actualmente las ciudades, participar activamente en la resolución de los mismos. Y, finalmente, no se puede olvidar que, si bien es comprensible que las gestiones edilicias no hayan dado aún los resultados esperados debido a que han tenido que dedicar gran parte de este período a enmendar los daños que dejaron sus predecesores, también lo es que esto no puede volverse una disculpa para posibles desaciertos en el tiempo venidero.

Los alcaldes de oposición, justamente por haberse postulado como únicas alternativas de un cambio verdadero y por haber sembrado en la población esperanzas por mejorar, están obligados a dar todo de sí para responder ante las comunidades salvadoreñas y así dar un paso hacia la erradicación de los vicios que han caracterizado a las administraciones areneras. ARENA continúa con el poder de 160 alcaldías; según lo que se ha visto hasta ahora, eso significa 160 municipios cuyas necesidades se diluyen entre la buroctacia y la comupción. Que ese dato sea suficiente para que los nuevos alcaldes trabajen duro y para que la sociedad civil no dude en darles su apoyo.

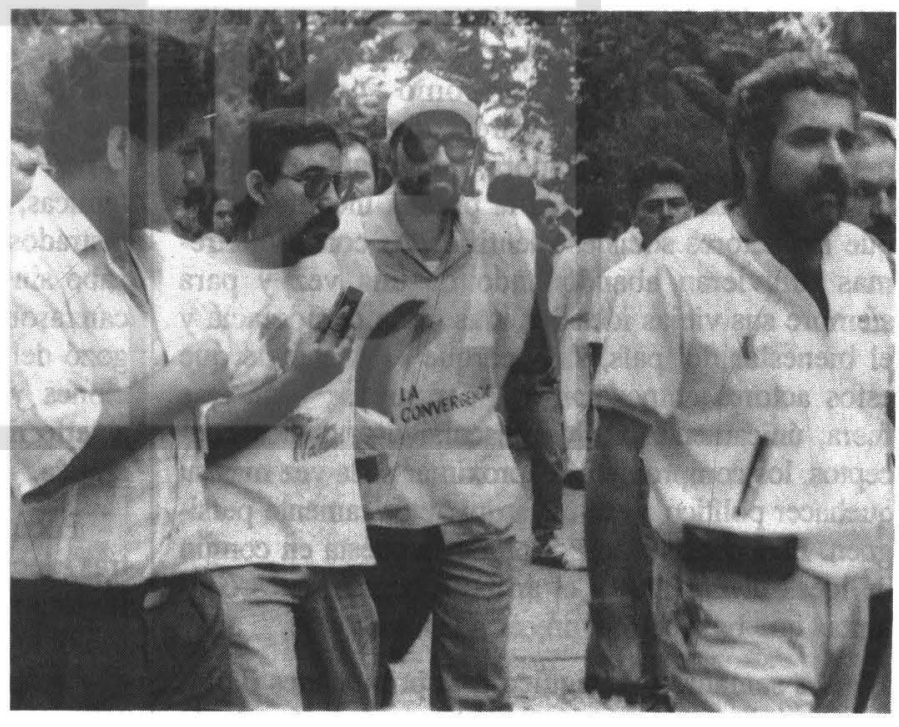




\section{La asamblea legislativa}

De la misma forma en que muchos salvadoreños depositaron su confianza en los alcaldes de oposición electos el 16 de marzo, sobre la nueva composición de la asamblea legislativa también se erigieron grandes expectativas. Había llegado el momento de poner fin a los monopolios políticos. ARENA se vería obligada a replantear su actitud, tanto frente al país como frente a su manera tradicional de desempeñarse en la política. El consenso empezaría a ser una realidad y los diputados se verían, al fin, obligados a preocuparse más por solucionar los problemas del país que por satisfacer sus intereses particulares.

Pasado este primer periodo cabría, pues, preguntarse qué tanto ha respondido el desempeño de la asamblea ante los grandes desafíos que le fueron planteados tras los resultados electorales. Para responder esa interrogante es necesario hacer un breve recuento de los aspectos más sobresalientes del desempeño del pleno. Durante el primer mes de labores, los diputados se mantuvieron enfrascados en la resolución de asuntos eminentemente administrativos. La elección consensuada del Presidente de la Junta Directiva y la configuración de las comisiones de trabajo - a pesar del "berrinche" protagonizado por los partidos de Conciliación Nacional y Demócrata Cristiano- constituyeron un primer paso hacia un desempeño legislativo que, ciertamente, distaría mucho de las prácticas de antaño, pero que se encuentra muy lejos aún de aproximarse a una práctica democrática real. De cualquier modo, en los escenarios en los que se desenvuelve la política - y en el ambiente de la opinión pública en general-, palabras como consenso y concertación ocuparon lugares privilegiados, cosa que no dejo de ser alentadora; no porque se creyera ingenuamente que esa era la prueba inequívoca de que los actores sociales identificados con las extremas estuvieran abandonando de una vez y para siempre sus viejas ideas en aras de la democracia y el bienestar del país, sino porque el hecho de que estos actores empezaran a hacer suyos -aunque fuera, únicamente, a nivel discursivo- dichos conceptos, los comprometía a aproximar cada vez más su quehacer político a esa meta que retoricamente persiguen. Esta consiste en posibilitar la puesta en común de ideas divergentes y el arribo a conclusiones conjuntas que busquen favorecer a las mayorías.

Las semanas que siguieron al primer mes de labores vinieron marcadas por la derogación de la Ley de Privatización de ANTEL, el impacto que ésta produjo y el esfuerzo que la comisión ad hoc llevó a cabo para ofrecer al país una ley ahora corregida y aumentada. La derogación trajo consigo, además de mejoras legales en el procedimiento de la privatización de la telefónica, serias implicaciones políticas. Para ARENA resultó ser la primera muestra palpable de que el poder, del que tantas veces hizo mal uso, había menguado considerablemente, pues ni siquiera el veto presidencial hubiera podido revertir la decisión de la oposición.

Con la reelaboración de la Ley, la asamblea legislativa dio muestras de entender que la privatización es un asunto serio en el cual se ponen en juego los bienes de la nación. Para los partidos que apoyaron la derogación fue importante asumir las consecuencias de la misma, pues si en la anterior asamblea era relativamente fácil ser oposición, ya que los errores eran rápida y fácilmente atribuibles a ARENA, ahora, al igual que el poder, la responsabilidad debe ser compartida por cada uno de los partidos. La derogación no significó únicamente una derrota para el partido en el gobiemo, sino también una prueba para los demás partidos, los cuales, además de estrenar su acrecentada cuota de poder, se vieron en la obligación de demostrar que realmente iban a usarla en beneficio del país.

Al tiempo que la comisión ad-hoc trabajaba en las mejoras a la Ley de Privatización de ANTEL, la comisión política de la asamblea iniciaba el debate con respecto a la elección de 16 magistrados de la Corte Suprema de Justicia (CSJ) y, entre ellos, el magistrado presidente del Organo Judicial. Una numerosa lista de nombres empezó a desfilar por los diarios nacionales $y$, aunque en un primer momento todo parecía indicar que la elección de los funcionarios sólo se llevaría a cabo después de largas polémicas, la renovación de la tercera parte de los magistrados de la Corte Suprema de Justicia se llevó a cabo sin tardanzas, gracias a que los diputados alcanzaron rápidamente el consenso. La elección gozó del beneplácito de la mayor parte de las fracciones y fue asumida por los políticos como un acierto más en el camino hacia la transición democrática.

Poco después explotó el escándalo financiero y, tras decidir el establecimiento de una comisión investigativa para contribuir al esclarecimiento del millonario fraude, fue ese escandalo el que acaparó - y acapara todavía - el quehacer legislativo en los últimos días. Ante el pleno han comparecido varios de los implicados en el caso FINSEPRO- 
INSEPRO, pero lo más polémico y espectacular ha sido la interpelación al presidente del Banco Central de Reserva, Roberto Orellana Milla. Quienes tuvieron la oportunidad de observar algunas imágenes de dicho evento, pudieron darse cuenta de la pobreza argumentativa de muchos de nuestros diputados y de que todavía es bastante frecuente que las fracciones se valgan de cualquier pretexto para "sacarse los trapos al sol", ventilar sus inquinas políticas y rivalizar con sus opositores.

Por estos motivos puede afirmarse que el sistema político salvadoreño está lejos todavía de superar sus atavismos más característicos y convertirse en eje del proceso de la transición democrática. En muchos casos, y en especial en los que grandes intereses políticos y económicos se ponen en juego, las reacciones viscerales continúan predominando sobre los análisis racionales. Hay que reconocer que el equilibrio de fuerzas logrado en las pasadas elecciones ha dado buenos resultados, en el sentido de que la asamblea legislativa actual es, a todas luces, más agresiva, protagónica y autónoma que las anteriores. Sin embargo, en momentos determinantes, como la interpelación recién pasada, resulta claro que a muchos de nuestros políticos les falta preparación y experiencia en los aspectos que constituyen una democracia real.

Cuando el nudo del escándalo financiero empiece a desatarse $y$ las fracciones legislativas puedan retomar sus propios asuntos, nuevos puntos polémicos, como la disminución del IVA y la nacionalización de la banca, se pondrán en discusión. Ojalá las experiencias de estos últimos cien días sean capitalizadas por los diputados de manera que su desempeño aumente en calidad y cobertura. Cosa que no sucederá si estos, a fuerza de repetir la palabra hasta el cansancio, se enfrasquen en creer que la concertación es ya una meta superada y que la asamblea legislativa de hoy es la que el país necesita.

Carmen Elena Villacorta Zuluaga 